\title{
UNA VISIÓN CRÍTICA DE LA RESPONSABILIDAD SOCIAL DE LA UNIVERSIDAD Y DE LAS EMPRESAS (2010)
}

seminario sobre responsabilidad social! Tengo la convicción de que los más graves problemas de México y del mundo son el resultado de la irresponsabilidad social, es decir, de la injusticia social.

En los últimos tiempos se han puesto de moda la ética, los valores, la responsabilidad social: se acaba de celebrar un congreso internacional con el lema: "Los valores son rentables". El grupo de filósofos dirigidos por Adela Cortina publica libros con títulos como La ética es rentable. Hay grupos especializados en formular códigos de ética, porque producen excelentes resultados financieros. Y ya solo falta que el Dow Jones o la BMV contraten asesores de ética para impulsar las acciones al alza.

Permítanme que, de entrada, manifieste mi indignación por la ofensa y degradación que se hace a la ética. Tal vez porque llevo más de 50 años dando clase de ética, me resulta como amiga entrañable (por supuesto que la responsabilidad social es parte relevante de la ética).

Mi enojo no es en contra de las personas que se expresan así, porque quiero suponer que lo hacen con buena intención. Mi enojo es en contra del absurdo de emplear la inmensa dignidad de la ética con fines mercantiles. Esto equivale a exaltar la gracia y belleza de una dama para después prostituirla.

Invocar a la ética (a la responsabilidad social) por rentable equivale a invocarla en contra de ella misma; equivale a la oración del 
ladrón: “ayúdame, Dios mío, para que mi robo resulte perfecto”. Equivale a la piadosa actitud del expresidente de Estados Unidos George Bush Sr. (de infeliz memoria), quien decía: "Como Dios no solo está a mi lado sino de mi lado, con su poder ganaremos esta guerra contra Irak". Lo que equivale a decir: Dios me ayudará a eliminar a todos los que se interpongan en mi camino hacia los pozos del oro negro. Sí, es cierto que las empresas que actúan con ética suelen tener un éxito mayor y más estable que las demás. Pero es muy diferente cuando el éxito es resultado de la observancia del código de ética que cuando se fabrican códigos de ética para tener ganancias.

Con frecuencia se publican en grandes desplegados premios a empresas socialmente responsables. Se califican y premian acciones como: protección al medio ambiente, atención a marginados, pintar fachadas de barrios pobres y hasta alguna construcción de escuelitas en rancherías. Se da la impresión de que la empresa es premiada por su altruismo o por sus obras de caridad.

Aquí quiero hacer una afirmación fundamental que se relaciona con el tema que nos ocupa: Ninguna institución, empresa o persona puede hablar de caridad si antes no ha cumplido con la justicia.

Cuando una institución, empresa o persona realiza obras de supuesta bondad o responsabilidad social y no ha hecho justicia en los distintos niveles institucionales, se puede decir que fabrica una cortina de humo para encubrir las injusticias internas.

A continuación, voy a referirme en apretada síntesis a la que me parece ser la responsabilidad social de la universidad y de la empresa.

Es responsabilidad de la universidad no ser apéndice del sistema, no ser empresa productora de paquetes humanos para la compraventa de profesionistas, no ser moldeadora de personalidades en serie ni engorda de cerebros, no ser amansadora de personas críticas y de rebeldes con causa, no ser instrumento de divisiones de clases sociales, no tratar a los estudiantes como mercancías demandadas por el mercado.

La responsabilidad social de la universidad es ser luz y proyectar luz, ser el recinto sagrado de la razón y el ámbito para pensar los problemas del mundo y a nosotros en el mundo, ser la conciencia crítica 
de la sociedad que denuncia y anuncia, ser oportunidad y auxilio en el desarrollo de humanidad, ser promotora del pensamiento crítico, de la imaginación para construir un mundo mucho mejor. La universidad debe ser agente activo del cambio social que favorezca la igualdad, la dignidad y la auténtica libertad de las personas; debe propiciar el crecimiento de estudiantes que sientan pasión por la justicia, por la verdad, por la paz; debe generar conocimiento, comunicarlo y beneficiar con él a la sociedad; debe propiciar el desarrollo del pensamiento crítico, de la imaginación y de la responsabilidad social de todos su miembros.

Ahora bien, ¿qué sentido tiene que las universidades no solo no cumplan su importantísima responsabilidad social, sino que cometan el imperdonable fraude al destruir la inmensa riqueza humana de nuestra juventud por preferir el dinero a la dignidad y potencialidad de los estudiantes? ¿Qué sentido tiene, pues, que estas universidades manden a sus alumnos a poner algunos tabiques o láminas en casas de indigentes para pagar a la sociedad lo que de ella han recibido?

Estas actitudes que realizan estas instituciones supuestamente para cumplir su deber de justicia hacia la sociedad deben calificarse de hipocresía y encubrimiento, y esta perversión es especialmente grave porque la cometen los que debieran ser la inteligencia y la conciencia del pueblo.

Y ahora, sobre la responsabilidad social de la empresa: la responsabilidad social de una empresa es constituirse en la gran familia productora de satisfactores de las necesidades propias y de la sociedad. $\mathrm{Su}$ primera obligación no es, como algunos piensan, producir ganancias; su más importante deber es procurar el bienestar y desarrollo de todos sus integrantes.

Los trabajadores deben ser tratados como personas, no como mercancías o medios de producción. Están muy equivocados los que piensan que tratar con respeto y consideración a los trabajadores conduce al fracaso económico. Don José María Arizmendiarrieta estableció este lema en las empresas Mondragón: "Aquí lo más importante es la persona y el capital es un instrumento a favor de las personas". Y esa empresa, que se inició con muy pocos trabajadores desempleados, 
actualmente es una muy próspera transnacional extendida por más de 20 países.

La empresa debe propiciar un trabajo que permita a los trabajadores el desarrollo de sus habilidades, de su creatividad, de su imaginación. Debe fomentar la participación de todos los integrantes de todos los niveles y, desde luego, que los salarios no se fijen de acuerdo con la oferta y la demanda, sino procurando la mínima distancia entre justicia conmutativa (lo que produce el trabajador) y justicia distributiva (según sus necesidades).

Pero, si en vez de eso la empresa es una estructura de poder compuesta por amos de la abundancia y esclavos de la necesidad, que pone el dinero por encima de las personas y usa a las personas como medios de producción de dinero; si se considera la gran obligación de la empresa producir ganancias que después, por los mecanismos de distribución del mercado, se conviertan en riqueza para todos (lo que es una gran mentira); si este sistema que domina al mundo funciona para privilegiar, para enriquecer a muy pocos con el sacrificio y destrucción de miles de millones de trabajadores (cada uno de los cuales vale más que todo el universo, en expresión de San Agustín), entonces todas esas empresas

234 infames necesitan trucos, maquillajes, engaños para ser aceptadas, para hacer amable su apariencia, para mostrarse como solícitas servidoras de la sociedad.

Por eso existen innumerables empresas trasnacionales y nacionales que invierten miles de millones de dólares para proyectar una imagen maravillosa de su responsabilidad social, del bien que hacen en el mundo, de su cara de bondad, de amabilidad, de caridad y hasta de sacrificio en favor de sus consumidores.

Necesitan construir una espesa cortina de humo para ocultar sus maquinaciones, a veces criminales, con las que amasan dinero y poder.

Los ejemplos son innumerables: Enron, Eskom, Monsanto, Walmart, Nike, Shell, Exxon Valdez, Citibank, Banamex, BBVA, McDonald, las de los refrescos de cola, General Electric, General Motors, AT\&T, Pfizer, Pemex, casi todas las maquiladoras y muchas más. 
Vean, por favor "The Corporation”, una excelente película sobre las empresas trasnacionales, sus hipocresías, venenos y, a veces, crímenes. Es un documental fruto de la investigación y coordinación de, entre otros, tres muy importantes y valientes analistas investigadores: Noam Chomsky, Naomi Klein y Michael Moore.

Vean también "La gran venta", que muestra la obsesión patológica de la privatización por orden del neoliberalismo. ¿Qué sentido tiene que el dueño de Nike regale medio millón de tenis defectuosos a niños africanos (que por cierto no usan zapatos) cuando explota a millones de trabajadores para multiplicar su inmensa fortuna?

Cuando Michael Moore preguntó a este archimillonario: ¿Se siente usted tranquilo de pagar 70 centavos de dólar por jornadas de diez horas? El cínico archimillonario contestó: estarían peor sin trabajo.

¿Qué sentido tiene que Walmart acumule premios de empresa socialmente responsable si sigue violando los derechos de las y los trabajadores, si sigue impidiendo la formación de sindicatos (no todos los sindicatos son perversos), si trata de manera abusiva a los proveedores, como consta en documentales llenos de evidencias y de testimonios irrefutables?

En Bolivia, por mandato del neoliberalismo, unas empresas compraron el derecho de propiedad sobre el agua. Se privatizó incluso el agua de la lluvia. Tuvo el pueblo que lanzarse a las calles y sublevarse contra el fraude e increíble arbitrariedad. La protesta costó muchos heridos y seis jóvenes muertos a palos por los policías.

¿Qué sentido cínico pudieron tener las piscinas que construyeron como expresión de su responsabilidad social esas empresas que habían monopolizado el agua de los ríos, de los lagos y hasta el agua que caía del cielo?

Es inaudito que para frenar este sistema de rapiña que, por la ambición del dinero, mata de hambre, y en este caso de sed, sea necesario acudir a la fuerza y a veces hasta a derramar la sangre.

La responsabilidad social de Monsanto es producir y ofrecer a millones de personas leche, productos lácteos sanos y nutritivos, pesticidas, semillas mejoradas de auténtica calidad. Ciertamente no lo hace; por 
el contrario, como lo demostraron dos prominentes funcionarios de la misma empresa, venden leche contaminada como efecto del Posilac que inyectan a las vacas, a las que afectan gravemente y que llegan a producir mastitis y a segregar supuración, que se mezcla en la ordeña con la leche y llega a ser venenosa.

De nada sirvió a los directivos querer sobornar a los denunciantes ni gastar más de 3000 millones de dólares para limpiar su imagen en los medios de comunicación.

Su poder sigue siendo abrumador y se extiende a innumerables campos con sus pesticidas y fertilizantes que dañan la tierra y han llegado a causar cáncer a personas que las aplican o aspiran... Monsanto, con el famoso agente naranja, usado en Vietnam, causó más de 50000 malformaciones de nacimiento y dañó a soldados estadounidenses que demandaron a esa compañía.

Estos procedimientos se extienden a muchísimos campos, incluidas las llamadas semillas mejoradas.

¿Qué sentido tienen las llamadas obras de caridad de esta poderosa trasnacional si viola las normas elementales de su responsabilidad social?

La responsabilidad social de las instituciones bancarias es dar solidez a la soberanía nacional que sabemos que no puede existir sin autosuficiencia económica. Su obligación es propiciar recursos a personas e instituciones solventes para fortalecer la producción, los empleos y la actividad económica de una nación.

¿Qué sentido tienen las llamadas obras de beneficencia de algunas instituciones bancarias cuando, lejos de cumplir su responsabilidad, se han convertido en estructuras de poder que tienen como máximo objetivo la ganancia económica, la avaricia sin límites (en expresión del presidente Obama) y que producen crisis tan mortales como la que estamos viviendo, que afectan principalmente a los más necesitados?

Horrible experiencia de esta obsesión por el lucro y el dinero ha experimentado México cuando los poderosos banqueros mexicanos solo por intereses y ventajas individualistas han vendido más del $80 \%$ del capital bancario mexicano, parte de la soberanía nacional real.

La responsabilidad social de las empresas televisoras, Televisa y TV Azteca, es informar, instruir, comunicar, divertir. ¿Qué sentido tienen 
las obras altruistas de estas compañías cuando lejos de cumplir sus deberes sociales, con sus programas y telenovelas enlodan los sagrados valores de la familia, de la tradición, del espíritu; ridiculizan el amor, la dignidad, la honestidad e imponen su nuevo código, su ideal de vida basado en la vulgaridad, en la glotonería, en el consumo compulsivo, en el hedonismo individualista?

Con su publicidad, subliminal o no pero siempre condicionante, pretenden (y lo están logrando) construir un mundo de marionetas manejadas por otras marionetas y todos manipulados por los grupos de poder.

Ante esta realidad, ¿qué sentido tienen las obras de responsabilidad de estas poderosas empresas?

Estos son solo unos cuantos ejemplos de lo que hace la enorme mayoría de las empresas trasnacionales, multinacionales y nacionales. Estas empresas desangran la economía y la dignidad de los países más necesitados, como lo muestran innumerables documentos y que hace muchos años denunciaba Eduardo Galeano en su excelente libro Las venas abiertas de América Latina.

Por otra parte, se suele decir que deben alabarse las obras buenas que se realizan para cumplir la responsabilidad social. Yo pienso, sin embargo, que no es éticamente bueno el aparente bien que se hace para encubrir el mal.

Finalmente, quiero subrayar que no estoy en contra de las obras que se realizan a favor de los más necesitados y para la conservación del planeta tierra (ojalá se realizaran más). Lo que me parece perverso, como lo he expresado, es que se quiera poner cara y sonrisa de Santa Claus a todas esas empresas que de hecho, son manejadas por el malvado Homo oeconomicus, obeso y obsceno, que pone el dinero por encima de las personas y usa a las personas para acumular dinero. 
CITAM Derechos Reservados.

La reproducción total o parcial de este artículo se podrá hacer si el ITAM otorga la autorización previamente por escrito. 